\title{
反映工艺条件对管式反应器催化反应影响的转化率方程
}

\author{
李巧灵 ${ }^{1}$, 张元华 ${ }^{1}$, 陈世萍 ${ }^{1}$, 方维平 ${ }^{1,2}$, 杨意泉 ${ }^{1,2}$ \\ 1 厦门大学化学化工学院化工系, 福建厦门 361005 \\ 2 厦门大学化学化工学院化学系醇醚酯清洁生产国家工程实验室, 福建厦门361005
}

摘要：根据幂指函数 $g(u)=u^{\mathrm{a}+b u}$ 的特点, 借用 “虚拟反应组分” 和 “变动级数” 的概念, 提出了管式反应器系统中反应转化率 与工艺条件的关系式 $X_{\mathrm{M}}=1-\exp \left[-\exp \left(\mathrm{A}+\mathrm{B} / T_{\mathrm{r}}+\mathrm{C} T_{\mathrm{r}}\right) p_{\mathrm{r}}^{n_{p 0}+n_{p 1} p_{\mathrm{r}}} \tau_{\mathrm{r}}^{n_{\tau 0}+n_{\tau 1} \tau_{\mathrm{r}}} \prod_{i=1}^{m} y_{i}^{n_{y 0}+n_{y 1} y_{i}}\right]$. 为了验证该转化率方程的普适性, 考察 了二乙苯催化脱氢、乙苯加氢和噻吩加氢脱硫等, 并利用 Matlab 软件分别对这三个催化体系的实验数据进行拟合. 结果表明, 此 方程在较宽的范围内均能很好地反映温度、反应压力、空速和物料比对转化率的影响. 预测结果与实验数据之间的总平均相对 偏差均小于 $2 \%$, 说明该方程并不是针对某一特定的催化反应或催化剂,可用于大多数的管式反应器催化反应系统中.

关键词: 转化率方程; 反应动力学; 加氢; 脱氢; 加氢脱硫; 阿伦尼乌斯法则

中图分类号: O643 文献标识码: A

\section{Development of a Novel Conversion Equation as a Function of Catalytic Reaction Conditions in Tubular Reactors}

\author{
LI Qiaoling ${ }^{1}$, ZHANG Yuanhua ${ }^{1}$, CHEN Shiping ${ }^{1}$, FANG Weiping ${ }^{1,2, *}$, YANG Yiquan ${ }^{1,2, \#}$ \\ ${ }^{1}$ Department of Chemical and Biochemical Engineering, College of Chemistry and Chemical Engineering, \\ Xiamen University, Xiamen 361005, Fujian, China \\ ${ }^{2}$ Department of Chemistry, College of Chemistry and Chemical Engineering and National Engineering Laboratory for Green Chemical \\ Production of Alcohols, Ethers and Esters, Xiamen University, Xiamen 361005, Fujian, China
}

\begin{abstract}
A comprehensive conversion equation was developed to simulate the catalytic reaction conditions (include temperature, pressure, residence time, and reaction composition) in tubular reactors: $X_{\mathrm{M}}=1-\exp \left[-\exp \left(\mathrm{A}+\mathrm{B} / T_{\mathrm{r}}+\mathrm{C} T_{\mathrm{r}}\right) p_{\mathrm{r}}^{n_{p 0}+n_{p 1} p_{\mathrm{r}}} \tau_{\mathrm{r}}^{n_{\tau 0}+n_{\tau 1} \tau_{\mathrm{r}}} \prod_{i=1}^{m} y_{i}^{n_{y 0}+n_{y 1} y_{i}}\right]$. This conversion equation is based on the characteristics of the power-exponential function $g(u)=u^{\mathrm{a}+\mathrm{b} u}$ as well as the "variable reaction order" and "virtual reactant" concepts. Its validity was verified by fitting experiment data from three different catalytic systems such as the dehydrogenation of diethyl benzene, the hydrogenation of ethylbenzene, and the hydrodesulfurization of thiophene. The results show that the influences of reaction temperature, pressure, residence time, and reactant composition on the conversion of the reactant can be determined within a wide range of values. By comparison with the experimental data, the calculated conversions were all found to have a total average relative deviation of less than $2 \%$. This suggests that the conversion equation is not limited to a specific catalyst system but could be suitable for various catalyst systems in tubular reactors.
\end{abstract}

Key words: conversion equation; reaction kinetics; hydrogenation; dehydrogenation; hydrodesulfurization; Arrhenius law

Much effort has been directed toward producing macroscopic kinetic models for various catalyst systems in indus- try [1-10]. For example, Hoang et al. [11] studied the influence of reaction conditions on the yield of hydrogen for

Received 23 October 2010. Accepted 22 December 2010.

*Corresponding author. Tel: +86-592-2186368; Fax: +86-592-2180361; E-mail: wpfang@xmu.edu.cn

\#Corresponding author. Tel: +86-592-2186368; Fax: +86-592-2180361; E-mail: yyiquan@xmu.edu.cn

Foundation item: Supported by the National Basic Research Program of China (973 Program, 2010CB226903).

English edition available online at ScienceDirect (http://www.sciencedirect.com/science/journal/18722067). 
the steam reforming of methane using a commercial $\gamma$-alumina supported sulfide nickel catalyst and they developed a two-dimensional model of the catalytic fixed-bed reformer. The predicted results from the reformer model agreed reasonably with the experimental data. This indicated that the kinetic data and the reforming model are reliable and can be used in the simulation and comprehensive analysis of an industrial reformer loaded with the same catalyst. A one-dimensional model for the oxidative coupling of methane (OCM) over a $\mathrm{La}_{2} \mathrm{O}_{3} / \mathrm{CaO}$ catalyst in a fixed-bed reactor has been developed by Tye et al. [12]. They tested their model under different operation modes and found that the OCM process that operates at a low $\mathrm{CH}_{4} / \mathrm{O}_{2}$ ratio and at an optimum temperature does not give a $\mathrm{C}_{2}$ (ethylene and ethane) product yield higher than $25 \%$. Therefore, other catalysts and reactor configurations should be investigated to obtain $\mathrm{C}_{2}$ products at higher yields. Alves et al. [13] proposed a mechanistic kinetic expression for the liquid-phase hydrogenation of 1-butyne over a commercial palladium-based catalyst. It was an eggshell type reaction under the chosen experimental conditions and this is close to the operating conditions in an industrial hydrorefining reactor. Based on the kinetic expression, the predicted data had a precision of $2.1 \%$. The kinetic parameters at $317 \mathrm{~K}$ and the activation energy were estimated with relative precision levels of $\pm 2.1 \%$ and $\pm 3.8 \%$, respectively. Although the macroscopic kinetic models mentioned above could successfully simulate practical operations they are only suitable for a specific catalyst system or a specific catalyst. Therefore, Zheng et al. [14] developed a general kinetic model for catalytic reaction conditions in tubular reactors and obtained satisfactory fitting results. However, they just considered the effect of temperature and residence time on conversion.

A novel conversion equation for use in most catalyst systems in tubular reactors is proposed in this article and the relationship between the conversion and temperature, pressure, residence time, and reactant composition is established.

\section{Kinetic model development}

For reactions that are isothermal, isochoric, plug-flow, and first-order irreversible, the conversion equation for a reactant $\mathrm{M}$ can be described as:

$$
X_{\mathrm{M}}=1-\exp (-k \tau)
$$

where $k$ is the rate constant and $\tau$ is the residence time. For most catalytic reaction systems, $k$ is related to the Arrhenius formula:

$$
k=k_{0} \exp \left(-E_{\mathrm{r}} / T_{\mathrm{r}}\right)
$$

where $E_{\mathrm{r}}$ is the relative activation energy and $T_{\mathrm{r}}$ is the rela- tive temperature.

When the catalyst system does not meet the above four requirements completely, the conversion equation can be written as:

$$
X_{\mathrm{M}}=1-\exp \left[-k \times f\left(y_{i}, p_{\mathrm{r}}, \tau_{\mathrm{r}}\right)\right]
$$

where $y_{i}$ denotes the mole fraction of the different reactants, $p_{\mathrm{r}}$ represents the relative pressure, and $\tau_{\mathrm{r}}$ is the relative residence time. The relativization of these variables makes the calculation more convenient.

Because of the complexity of heterogeneous catalyst systems, it is necessary to transform the Arrhenius formula to:

$$
k=\exp ^{\mathrm{A}+\mathrm{B} / T_{\mathrm{r}}+\mathrm{C} T_{\mathrm{r}}}
$$

When $\mathrm{C}=0$ and $\mathrm{B}<0$, Eq. (4) reduces to the Arrhenius formula.

The following discussion is concerned with the specific expression for the function $f\left(y_{i}, p_{\mathrm{r}}, \tau_{\mathrm{r}}\right)$. For simplification, we assume that each variable in the function $f\left(y_{i}, p_{\mathrm{r}}, \tau_{\mathrm{r}}\right)$ can be separated and we thus obtain:

$$
f\left(y_{i}, p_{\mathrm{r}}, \tau_{\mathrm{r}}\right)=f_{1}\left(y_{i}\right) f_{2}\left(p_{\mathrm{r}}\right) f_{3}\left(\tau_{\mathrm{r}}\right)
$$

In terms of the reaction order, when $m$ kinds of substances exist in the reaction system the function $f_{1}\left(y_{i}\right)$ can be expressed as:

$$
f_{1}\left(y_{i}\right)=\prod_{i=1}^{m} y_{i}^{n_{i}}
$$

However, in the practical application of Eq. (6) two problems exist: one is that $y_{i}^{n_{i}}$ can be multiplied by $k$ only when the concentration of reactant $i$ is constant at different positions in the catalyst bed. The other is that the reaction order $n_{i}$ will not remain constant in some complex catalytic reaction systems and, therefore, $n_{i}$ should be adjusted. If $n$ changes linearly with $y_{i}$, we obtain:

$$
n_{i}=n_{i 0}+n_{i 1} y_{i}
$$

Therefore, Eq. (6) can be rewritten as:

$$
f_{1}\left(y_{i}\right)=\prod_{i=1}^{m} y_{i}^{\left(n_{i 0}+n_{i 1} y_{i}\right)}
$$

The two other functions, $f_{2}\left(p_{\mathrm{r}}\right)$ and $f_{3}\left(\tau_{\mathrm{r}}\right)$, can be expressed in a similar manner by regarding variables $p_{\mathrm{r}}$ and $\tau_{\mathrm{r}}$ as virtual reactants:

$$
\begin{gathered}
f_{2}\left(p_{\mathrm{r}}\right)=p_{\mathrm{r}}^{n_{p 0}+n_{p 1} p_{\mathrm{r}}} \\
f_{3}\left(\tau_{\mathrm{r}}\right)=\tau_{\mathrm{r}}^{n_{\tau 0}+n_{\tau 1} \tau_{\mathrm{r}}}
\end{gathered}
$$

Hence, the conversion equation with respect to reaction conditions can be rewritten as:

$$
\begin{gathered}
X_{\mathrm{M}}=1-\exp \left[-\exp ^{\left(\mathrm{A}+\mathrm{B} / T_{\mathrm{r}}+\mathrm{C} T_{\mathrm{r}}\right)}\right. \\
\left.p_{\mathrm{r}}^{n_{p 0}+n_{p 1} p_{\mathrm{r}}} \tau_{\mathrm{r}}^{n_{\tau 0}+n_{\tau 1} \tau_{\mathrm{r}}} \prod_{i=1}^{m} y_{i}^{n_{y 0}+n_{y 1} y_{i}}\right]
\end{gathered}
$$

The derivation process for this new conversion equation is general, consequently, it can be applied to various catalytic reaction systems. 


\section{Application examples}

\subsection{Catalytic dehydrogenation of diethylbenzene (DEB)}

The catalyst used in this experiment was the commercial iron-based XH catalyst and it was supplied by the chemical factory at Xiamen University. The dehydrogenation reaction of DEB was carried out at atmospheric pressure ( $p_{\mathrm{r}}$ is constant) in a tubular reactor containing $10 \mathrm{ml}$ of the catalyst and the other experimental conditions were: temperature from $898-938 \mathrm{~K}$, residence time from $2.34 \times 10^{-2}-11.72 \times$ $10^{-2}$ min, reactant composition $\mathrm{H}_{2} \mathrm{O} / \mathrm{DEB}$ volume ratio from 1-5. The experimental results are shown in Table 1, where $X_{\text {exp }}$ and $X_{\text {cal }}$ denote the experimental conversion and the calculated conversion, respectively, and RD is the absolute relative deviation.

Table 1 Effect of reaction conditions on conversion during the catalytic dehydrogenation of DEB

\begin{tabular}{cccccc}
\hline$T_{\mathrm{r}}$ & $\lambda_{\mathrm{r}}$ & $\tau_{\mathrm{r}}$ & $X_{\exp } / \%$ & $X_{\text {cal }} / \%$ & $\mathrm{RD} / \%$ \\
\hline 0.9574 & 0.8 & 0.25 & 75.3 & 73.2 & 2.86 \\
0.9680 & 0.8 & 0.25 & 78.2 & 80.1 & 2.47 \\
0.9787 & 0.8 & 0.25 & 83.2 & 86.2 & 3.62 \\
0.9893 & 0.8 & 0.25 & 89.6 & 91.1 & 1.62 \\
1.0000 & 0.8 & 0.25 & 96.1 & 94.7 & 1.48 \\
0.9680 & 0.2 & 0.25 & 44.3 & 43.6 & 1.57 \\
0.9680 & 0.4 & 0.25 & 51.2 & 53.1 & 3.72 \\
0.9680 & 0.6 & 0.25 & 65.2 & 65.5 & 0.48 \\
0.9680 & 0.8 & 0.25 & 82.0 & 80.1 & 2.27 \\
0.9680 & 1.0 & 0.25 & 91.9 & 92.8 & 0.98 \\
0.9680 & 0.8 & 0.20 & 75.9 & 75.7 & 0.26 \\
0.9680 & 0.8 & 0.25 & 82.0 & 80.1 & 2.27 \\
0.9680 & 0.8 & 0.33 & 86.4 & 85.1 & 1.55 \\
0.9680 & 0.8 & 0.50 & 90.3 & 90.8 & 0.54 \\
0.9680 & 0.8 & 1.00 & 95.6 & 95.7 & 0.03 \\
\hline
\end{tabular}

Because an increase in temperature is beneficial to this endothermic reaction in terms of kinetics and thermodynamics, $k$ is accorded with the Arrhenius formula and Eq. (11) can be simplified to:

$$
X_{\mathrm{DEB}}=1-\exp \left[-\exp ^{\left(\mathrm{A}+\mathrm{B} / T_{\mathrm{r}}\right)} \tau_{\mathrm{r}}^{n_{\tau 0}+n_{\tau 1} \tau_{\mathrm{r}}} \lambda_{\mathrm{r}}^{n_{\lambda 0}+n_{\lambda 1} \lambda_{\mathrm{r}}}\right]
$$

Using Matlab software to fit the experimental data, we obtain:

$$
\begin{gathered}
X_{\mathrm{DEB}}=1-\exp \left[-\exp ^{\left(20.2649-18.0374 / T_{\mathrm{r}}\right)}\right. \\
\left.\tau_{\mathrm{r}}^{0.5613-0.3295 \tau_{\mathrm{r}}} \lambda_{\mathrm{r}}^{0.5352+2.0601 \lambda_{\mathrm{r}}}\right]
\end{gathered}
$$

The simulation program was run with different input data for one variable to validate the model. The other two variables were kept constant. Typical modeling results and a comparison with the experimental data at different temperatures, $\mathrm{H}_{2} \mathrm{O}$ /DEB volume ratios and residence times are shown in Figs. 1-3. These figures show the good predictive

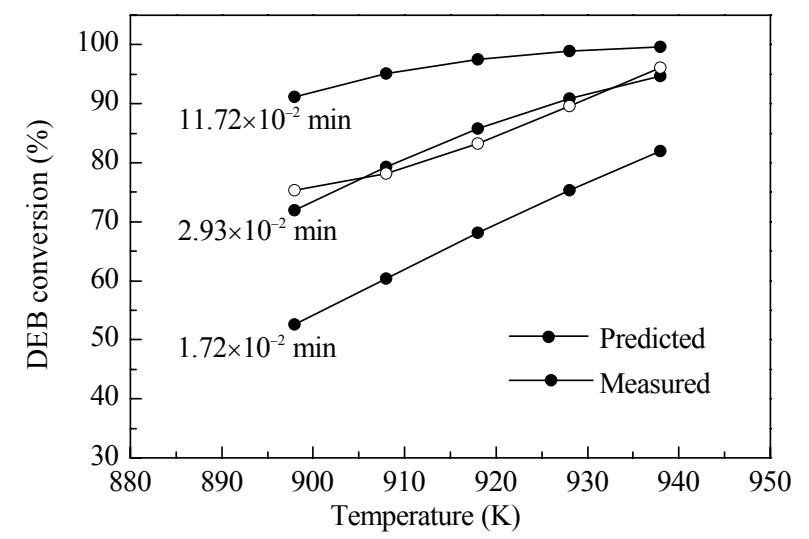

Fig. 1. Comparison of the predicted and measured conversion vs temperature at different residence time with a $\mathrm{H}_{2} \mathrm{O} / \mathrm{DEB}$ volume ratio of 4 .

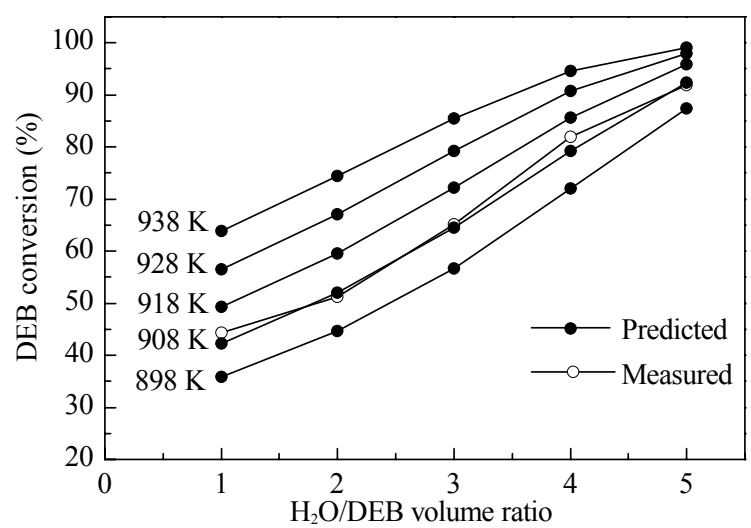

Fig. 2. Comparison of the predicted and measured conversion vs the $\mathrm{H}_{2} \mathrm{O} / \mathrm{DEB}$ volume ratio at different temperatures. The residence time was $2.93 \times 10^{-2} \mathrm{~min}$.

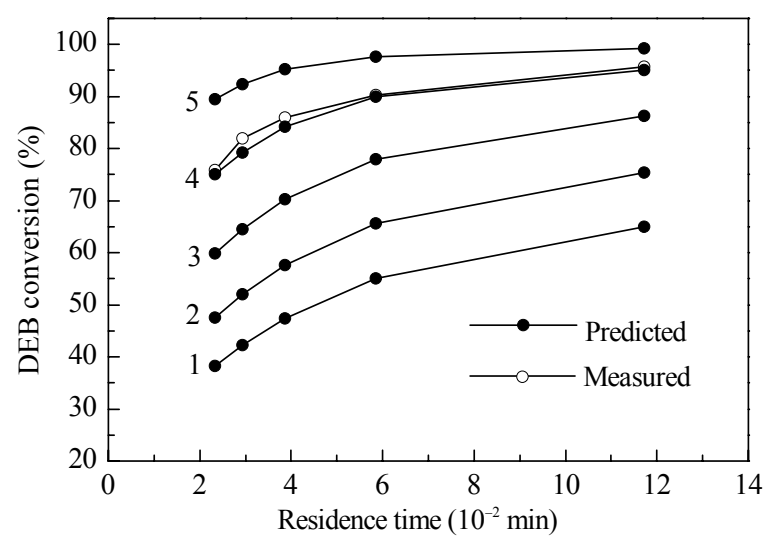

Fig. 3. Comparison of the predicted and measured conversion vs residence time at different $\mathrm{H}_{2} \mathrm{O} / \mathrm{DEB}$ volume ratios. The temperature was $908 \mathrm{~K}$.

ability of this equation with an average relative deviation (ARD) of $1.72 \%$. It is also clear that temperature, residence time, and $\mathrm{H}_{2} \mathrm{O} / \mathrm{DEB}$ volume ratios have a positive effect in improving DEB conversion, and this is consistent with the results reported by Bai [15]. 


\subsection{Catalytic hydrogenation of ethylbenzene (EB)}

The kinetics of aromatic hydrogenation has been reported previously [16,17], however, our experiment was only concerned with the catalytic hydrogenation of EB. The catalyst used in our experiment was $0.13 \mathrm{~g}$ of unsupported MoWNi, and the experimental apparatus used has been reported previously [18]. The $\mathrm{H}_{2}$ flow rate was maintained at a constant $100 \mathrm{ml} / \mathrm{min}$, the temperature ranged from $373-573 \mathrm{~K}$, and the pressure ranged from $0.1-4 \mathrm{MPa}$. The residence time varied from $9.2037 \times 10^{-4}$ to $9.7197 \times 10^{-4} \mathrm{~min}$ and the ethylcyclohexane/EB molar ratio was $0.2-1$. The experimental results are listed in Table 2.

Table 2 Effect of reaction conditions on conversion in the catalytic hydrogenation of $\mathrm{EB}$

\begin{tabular}{ccccccc}
\hline$T_{\mathrm{r}}$ & $p_{\mathrm{r}}$ & $\lambda_{\mathrm{r}}$ & $\tau_{\mathrm{r}}$ & $X_{\text {exp }} / \%$ & $X_{\text {cal }} / \%$ & $\mathrm{RD} / \%$ \\
\hline 0.6509 & 0.25 & 0.6 & 0.6602 & 23.0 & 23.6 & 2.43 \\
0.7382 & 0.25 & 0.6 & 0.6602 & 50.3 & 50.4 & 0.10 \\
0.8255 & 0.25 & 0.6 & 0.6602 & 68.1 & 68.2 & 0.18 \\
0.9127 & 0.25 & 0.6 & 0.6602 & 71.4 & 74.0 & 3.64 \\
1.0000 & 0.25 & 0.6 & 0.6602 & 72.5 & 71.0 & 2.01 \\
0.7382 & 0.025 & 0.6 & 0.6602 & 29.3 & 29.1 & 0.76 \\
0.7382 & 0.25 & 0.6 & 0.6602 & 50.3 & 50.4 & 0.09 \\
0.7382 & 0.50 & 0.6 & 0.6602 & 59.5 & 58.6 & 1.48 \\
0.7382 & 0.75 & 0.6 & 0.6602 & 65.4 & 64.6 & 1.32 \\
0.7382 & 1.00 & 0.6 & 0.6602 & 69.3 & 69.9 & 0.82 \\
0.7382 & 0.25 & 0.2 & 0.6602 & 69.5 & 69.7 & 0.32 \\
0.7382 & 0.25 & 0.4 & 0.6602 & 58.4 & 57.6 & 1.44 \\
0.7382 & 0.25 & 0.6 & 0.6602 & 50.3 & 50.4 & 0.10 \\
0.7382 & 0.25 & 0.8 & 0.6602 & 45.4 & 45.2 & 0.37 \\
0.7382 & 0.25 & 1.0 & 0.6602 & 41.3 & 41.2 & 0.16 \\
0.7382 & 0.25 & 0.6 & 1.0000 & 70.1 & 70.2 & 0.12 \\
0.7382 & 0.25 & 0.6 & 0.8118 & 61.2 & 61.0 & 0.28 \\
0.7382 & 0.25 & 0.6 & 0.6602 & 50.3 & 50.4 & 0.09 \\
0.7382 & 0.25 & 0.6 & 0.5387 & 39.4 & 39.7 & 0.66 \\
0.7382 & 0.25 & 0.6 & 0.4411 & 30.2 & 30.1 & 0.37 \\
\hline & & & & & &
\end{tabular}

Using Matlab software to fit the experimental data, we obtained:

$$
\begin{aligned}
& X_{\mathrm{EB}}=1-\exp \left[-\exp ^{\left(27.3639-12.1125 / T_{\mathrm{r}}-14.227 T_{\mathrm{r}}\right)}\right. \\
& \left.p_{\mathrm{r}}^{0.3334+0.2193 p_{\mathrm{r}}} \tau_{\mathrm{r}}^{1.8318-0.7792 \tau_{\mathrm{r}}} \lambda_{\mathrm{r}}^{-0.4851-0.0901 \lambda_{\mathrm{r}}}\right]
\end{aligned}
$$

here, the ARD was $0.84 \%$ suggesting that a high fitting accuracy was obtained. Equation (14) shows that the conversion decreased significantly when the residence time was shorter and increased with temperature and pressure. Moreover, the ethylcyclohexane/EB molar ratio $(\lambda)$ also influenced the conversion but not as remarkably as the other factors. Additionally, an increase of ethylcyclohexane in the inlet mixture led to a decrease in conversion suggesting that $\lambda$ inhibits the forward reaction. Therefore, the $\lambda$ fitting indexes in Eq. (14) are negative $\left(n_{\lambda 0}<0, n_{\lambda 1}<0\right)$.

\subsection{Catalytic hydrodesulfurization of thiophene (TP)}

For environmental protection the requirement to produce high-quality gasoline and diesel oil by especially reducing the sulfur content in oil products is of interest. Consequently, research is required on the quantitative relationship between the conversion of sulfur-containing compounds and the operating conditions chosen. Wang et al. [19] studied the HDS of benzothiophene and dihydrobenzothiophene over sulfided $\mathrm{Mo} / \mathrm{Al}_{2} \mathrm{O}_{3}$. The catalyst used in our experiment consisted of $500 \mathrm{mg}$ of $\mathrm{MoNiP} / \mathrm{Al}_{2} \mathrm{O}_{3}$ and the experimental apparatus has been reported elsewhere [20]. The reaction conditions were as follows: temperature from 513 to $573 \mathrm{~K}$, hydrogen partial pressure from 0.5 to $2.2 \mathrm{MPa}$, residence time from $8.46 \times 10^{-3}$ to $67.7 \times 10^{-3} \mathrm{~min}$ and hydrogen/TP volume ratio from 225 to 700 . The experimental results are shown in Table 3.

Table 3 Effect of reaction conditions on conversion in the catalytic hydrodesulfurization of TP

\begin{tabular}{ccccccc}
\hline$T_{\mathrm{r}}$ & $p_{\mathrm{r}}$ & $\lambda_{\mathrm{r}}$ & $\tau_{\mathrm{r}}$ & $X_{\text {exp }} / \%$ & $X_{\mathrm{cal}} / \%$ & $\mathrm{RD} / \%$ \\
\hline 0.8953 & 0.5 & 0.5 & 0.25 & 22.4 & 22.1 & 1.17 \\
0.9300 & 0.5 & 0.5 & 0.25 & 53.1 & 54.6 & 2.74 \\
0.9651 & 0.5 & 0.5 & 0.25 & 88.6 & 89.6 & 1.17 \\
1.0000 & 0.5 & 0.5 & 0.25 & 99.6 & 99.7 & 0.03 \\
0.9651 & 0.2272 & 0.5 & 0.25 & 87.3 & 86.6 & 0.84 \\
0.9651 & 0.5 & 0.5 & 0.25 & 92.1 & 89.9 & 2.38 \\
0.9651 & 0.6818 & 0.5 & 0.25 & 95.9 & 93.4 & 2.59 \\
0.9651 & 1.0 & 0.5 & 0.25 & 98.1 & 98.4 & 0.29 \\
0.9651 & 0.5 & 0.3214 & 0.25 & 74.1 & 74.0 & 0.18 \\
0.9651 & 0.5 & 0.6429 & 0.25 & 90.0 & 95.6 & 6.17 \\
0.9651 & 0.5 & 0.7857 & 0.25 & 99.5 & 98.1 & 1.38 \\
0.9651 & 0.5 & 1.0 & 0.25 & 99.3 & 99.5 & 0.23 \\
0.9651 & 0.5 & 0.5 & 1.00 & 99.6 & 99.6 & 0.00 \\
0.9651 & 0.5 & 0.5 & 0.25 & 87.3 & 89.9 & 2.99 \\
0.9651 & 0.5 & 0.5 & 0.17 & 80.2 & 78.3 & 2.42 \\
0.9651 & 0.5 & 0.5 & 0.125 & 65.4 & 66.6 & 1.82 \\
\hline
\end{tabular}

Using Matlab software to fit the experimental data, we obtain:

$$
\begin{gathered}
X_{\mathrm{TP}}=1-\exp \left[-\exp ^{\left(46.8584-34.4611 / T_{\mathrm{r}}-8.3094 T_{\mathrm{r}}\right)}\right. \\
\left.p_{\mathrm{r}}^{0.1855+1.3244 p_{\mathrm{r}}} \tau_{\mathrm{r}}^{0.921-1.1499 \tau_{\mathrm{r}}} \lambda_{\mathrm{r}}^{1.2048+0.0355 \lambda_{\mathrm{r}}}\right]
\end{gathered}
$$

here, the ARD was $1.65 \%$. In this case, a higher conversion of TP was obtained at higher temperature, which improved by nearly $10 \%$ and even $35 \%$ as the temperature was increased by $20 \mathrm{~K}$ implying that the $\mathrm{MoNiP} / \mathrm{Al}_{2} \mathrm{O}_{3}$ catalyst had superior performance. The short residence time resulted in a decrease in the conversion. A positive effect was noticed for an increase in the hydrogen partial pressure and increasing the $\mathrm{H}_{2} / \mathrm{TP}$ volume ratio favored TP conversion. However, when the conversion was high the effect of the $\mathrm{H}_{2} / \mathrm{TP}$ volume ratio was weak. 


\section{Conclusions}

A novel conversion equation is proposed based on the "variable reaction order" and "virtual reactant" concepts. Three examples of catalytic reactions are given and the average relative derivation after fitting the experimental data was less than $2 \%$. This indicates that the new equation can be used to describe the quantitative relationship between reactant conversion and reaction conditions with satisfactory precision for various catalytic reaction systems.

\section{Nomenclature}

A: model parameter

ARD: average relative deviation, $\%$

B: model parameter

C: model parameter

$E_{\mathrm{r}}$ : relative activation energy

$k$ : rate constant

$n_{i 0}, n_{i 1}, n_{p 0}, n_{p 1}, n_{\tau 0}, n_{\tau 1}$ : model parameters

$p$ : pressure, $\mathrm{MPa}$

$p_{\mathrm{r}}$ : relative pressure $\left(p_{\mathrm{r}}=p / p_{\max }\right)$

$\mathrm{RD}$ : relative deviation, $\%$

$T$ : temperature, $\mathrm{K}$

$T_{\mathrm{r}}$ : relative temperature $\left(T_{\mathrm{r}}=T / T_{\max }\right)$

$X_{\mathrm{M}}$ : conversion of reactant $\mathrm{M}, \%$

$y_{i}$ : molar fraction of species $i, \%$

$\tau$ : residence time, min

$\tau_{\mathrm{r}}:$ relative residence time $\left(\tau_{\mathrm{r}}=\tau / \tau_{\max }\right)$

$\lambda$ : material ratio

$\lambda_{\mathrm{r}}$ : relative material ratio $\left(\lambda_{\mathrm{r}}=\lambda / \lambda_{\max }\right)$

\section{Subscript}

cal: calculated value exp: experimental value r: relative value

\section{References}

1 米冠杰, 李建伟, 邱东, 陈标华. 催化学报 (Mi G J, Li J W, Qiu D, Chen B H. Chin J Catal), 2010, 31: 547

2 宋树芹, 王毅, 沈培康. 催化学报 (Song Sh Q, Wang Y, Shen P K. Chin J Catal), 2007, 28: 752

3 王敏, 李军, 桑雪梅, 谢家庆. 催化学报 (Wang M, Li J, Sang X M, Xie J Q. Chin J Catal), 2007, 28: 383

4 Barkat M, Nibou D, Chegrouche S, Mellah A. Chem Eng Process, 2009, 48: 38

5 Kvamsdal H M, Jakobsen J P, Hoff K A. Chem Eng Process, 2009, 48: 135

6 Boehme T R, Onder C H, Guzzella L G. Comput Chem Eng, 2008, 32: 2445

7 Jaree A, Boonsomlanjit B, Limtrakul J. Comput Chem Eng, 2008, 32: 2897

8 Akpan E, Akande A, Aboudheir A, Ibrahim H, Idem R. Chem Eng Sci, 2007, 62: 3112

9 Visconti C G, Tronconi E, Lietti L, Zennaro R, Forzatti P. Chem Eng Sci, 2007, 62: 5338

10 Quiney A S, Schuurman Y. Chem Eng Sci, 2007, 62: 5026

11 Hoang D L, Chan S H, Ding O L. Chem Eng J, 2005, 112: 1

12 Tye C T, Mohamed A R, Bhatia S. Chem Eng J, 2002, 87: 49

13 Alves J A, Bressa S P, Martine O M, Barreto G F. Chem Eng J, 2007, 125: 131

14 郑泉兴, 刘纪端, 王琪, 杨意泉, 方维平, 张鸿斌. 化学反 应工程与工艺(Zheng Q X, Liu J D, Wang Q, Yang Y Q, Fang W P, Zhang H B. Chem React Eng Technol), 2005, 21: 360

15 白雪. 上海化工(Bai X. Shanghai Chem Ind), 1985, 3: 29

16 Wang J, Huang L M, Li Q Zh. Appl Catal A, 1998, 175: 191

17 Bertero N M, Apesteguia C R, Marchi A J. Appl Catal A, 2008, 349: 100

18 盛景云. [博士学位论文]. 厦门: 厦门大学 (Sheng J Y. [PhD Dissertation]. Xiaman: Xiaman Univ), 2007

19 Wang H M, Prins R. Appl Catal A, 2008, 350: 191

20 林凌. [硕士学位论文]. 厦门：厦门大学 (Lin L. [MS Dissertation]. Xiaman: Xiaman Univ), 2007 